\title{
Uma análise sobre a importância de um projeto com ações direcionadas ao acolhimento de ingressantes de cursos de Computação: Um estudo qualitativo
}

\author{
Marina da S. Rocha, Karina Castelo Branco, Ana Lara S. Oliveira, Lauana M. C. \\ de Oliveira, Maria Victoria S. Fiori, Jacilane de H. Rabelo, Anna Beatriz Marques \\ Universidade Federal do Ceará (Campus Russas) - Russas, CE - Brasil \\ \{marinarocha, karinascb, analara, lauanacartaxo, \\ victoria.fiori\}@alu.ufc.br, \{jacilane.rabelo, beatriz.marques\} @ufc.br
}

\begin{abstract}
The dropoutt of female students in the first semesters of Computer Science courses is becoming increasingly frequent. Thus, we are seeking to increase the number of actions that engage, support and welcome female students in the first semesters. Based on this, the academic mentoring initiative is an action that aims to identify and analyze the main difficulties and motivations of the incoming students in order to develop activities that can change this reality and provide the necessary support. This paper presents a survey with the objective of collecting feedback from nine female students of the Computer Science and Software Engineering courses participating in an academic mentoring initiative. A qualitative analysis, using Grounded Theory methodology, was conducted to explore the impact of the initiative and suggestions for improvement.
\end{abstract}

Resumo. A evasão de alunas nos primeiros semestres dos cursos de Computação vem sendo cada vez mais frequente. Desse modo, busca-se tornar mais presentes ações que engajem, apoiem e acolham as alunas nos semestres iniciais. Partindo disso, a iniciativa de apadrinhamento acadêmico é uma ação que tem como objetivo identificar e analisar as principais dificuldades e motivações das alunas ingressantes para assim, desenvolver atividades que possam mudar essa realidade e fornecer o apoio necessário. Este artigo apresenta uma pesquisa que teve como objetivo coletar o feedback de nove alunas dos cursos de Ciência da Computação e Engenharia de Software participantes de uma iniciativa de apadrinhamento acadêmico. Uma análise qualitativa, por meio da metodologia Grounded Theory, foi realizada para explorar o impacto da iniciativa e sugestões de melhorias.

\section{Introdução}

As tendências atuais mostram que a exclusão digital está aumentando e as mulheres estão representadas de maneira insuficiente nas áreas de tecnologia (ONU, 2019). Segundo dados do Instituto Brasileiro de Geografia e Estatística (IBGE), apenas 20\% das pessoas atuantes na área são mulheres. Estatísticas mostram que em 2019, 50.000 mulheres se matricularam em cursos na área de Computação, um número baixo se comparado às matrículas de homens, que ultrapassam os 350.000 (SBC, 2019).

Dados divulgados pela Pesquisa Nacional por Amostra de Domicílios (PNAD) apontam que $79 \%$ das alunas dos cursos relacionados à Tecnologia da Informação (TI) desistem no primeiro ano (Programaria, 2021). O projeto de extensão It Girls da Universidade Federal da Paraíba, trabalha com ações que envolvem palestras sobre a história das mulheres na computação, rodas de conversas, oficinas e treinamentos sobre programação para estimular as alunas da área da TI, criando uma rede de apoio para estudantes e assim minimizar a evasão das alunas (Brito, 2020). 
Uma análise conduzida pelas coordenações do curso de Ciência da Computação (CC) e Engenharia de Software (ES) da Universidade Federal do Ceará - Campus de Russas, observou que apenas $20 \%$ das vagas ofertadas foram preenchidas por mulheres. Além disso, a média de evasão de mulheres no curso de ES era igual a $40 \%$ e no curso de CC era igual a 70\%. Visando contornar esse cenário, o projeto de pesquisa e extensão Meninas Digitais do Vale iniciou o apadrinhamento acadêmico, com o intuito de acolher e promover interação com alunas ingressantes dos cursos de CC e ES.

Após um ano do início do apadrinhamento acadêmico, as alunas apadrinhadas participaram de uma pesquisa baseada em entrevistas com o intuito de: (1) identificar as experiências do primeiro semestre, (2) identificar fatores motivacionais à permanência no curso, (3) identificar a participação em eventos promovidos pelo projeto/universidade e (4) identificar sugestões para melhoria da iniciativa.

Com os dados obtidos, foi realizada uma análise qualitativa utilizando a metodologia Teoria Fundamentada nos Dados, que consiste em uma abordagem para analisar dados a partir da codificação (Corbin e Strauss, 2014). A análise permitiu identificar as principais dificuldades das alunas no primeiro semestre, os fatores que as motivam a continuar no curso e sugestões de ações que podem influenciar positivamente na permanência e engajamento dessas estudantes nos semestres iniciais.

O restante do artigo está organizado da seguinte maneira: A Seção 2 apresenta os trabalhos relacionados. A Seção 3 descreve como ocorreu o apadrinhamento acadêmico. A Seção 4 relata a metodologia utilizada na análise qualitativa. A Seção 5 apresenta os resultados. A Seção 6 apresenta a discussão e por fim, são apresentadas as considerações finais e trabalhos futuros na Seção 7.

\section{Trabalhos Relacionados}

Diante da grande disparidade de gênero nos cursos de graduação, é de suma importância propostas de intervenções que estimulem a participação e permanência de mulheres em cursos de graduação, principalmente quando refere-se à computação. Por meio de pesquisas no Google Scholar, foram identificados estudos relacionados às iniciativas de apoio às ingressantes nos cursos de graduação relacionados à área de TI. Os estudos serão resumidamente descritos nesta seção.

Bordin et al. (2020) relatam uma experiência de tutoria das ingressantes dos cursos de Engenharia de Software e Ciência da Computação analisando os resultados das impressões dos discentes e docentes. Ao verificar as dificuldades gerais das estudantes do primeiro semestre, destacou-se a dificuldade de obter bom desempenho e o desconhecimento da realidade do curso, sendo estes fatores ligados à permanência ou desistência das discentes. Diante disso torna-se necessário realizar verificações constantes das experiências das estudantes para estimular a permanência nos cursos.

Louzada et al. (2019) abordam a importância do papel feminino na História da Computação, tendo em vista a necessidade da desmistificação de rótulos atribuídos às mulheres quando relacionadas ao âmbito tecnológico. Em razão da necessidade de ações que promovam iniciativas de incentivo e permanência das estudantes em cursos de graduação, o estudo propõe cinco categorias de atividades a serem conduzidas: (1) capacitação tecnológica; (2) construção humana; (3) divulgação científica; (4) representação e ampliação de alcance; e (5) promoção de eventos. Com a realização das atividades, como palestras e rodas de conversas na categoria de construção humana, foi 
possível identificar dados que realçam de forma positiva a eficácia dessas ações e o bom engajamento das participantes nos eventos. Esses dados foram coletados através de questionários que buscavam descobrir sobre o interesse em participar de novas ações promovidas, sugestões e a relevância sobre eventos desse porte.

Franzoia et al. (2019) realizaram um estudo com objetivo de: (1) investigar fatores de influência na reprovação de mulheres na disciplina de Introdução à Programação; (2) minimizar os fatores identificados por meio de um Grupo de Estudos em Programação, para introdução na linguagem Python. O estudo apresentou resultados satisfatórios, pois todas as estudantes consideraram que após o curso começaram a gostar de programação e um pouco mais de 75\% obtiveram notas superiores a 7,0.

Silva et al. (2018) relatam a execução de cinco estratégias que buscam incentivar a permanência e o sucesso de mulheres na área tecnológica: (1) reuniões mensais ou sob demanda das estudantes mulheres; (2) realização de ações socioeducativas; (3) envolvimento das estudantes em projetos de pesquisa e extensão; (4) participação de estudantes em competições de Tecnologia da Informação e Comunicação (TIC); e (5) pesquisa científica sobre Mulheres em TIC. Apesar de serem apresentados resultados como a apresentação de trabalhos em eventos, não foi realizada uma avaliação sobre o impacto das ações do ponto de vista das participantes.

Alves et al. (2017) relatam uma experiência com técnicas de aprendizagem colaborativa para incentivar o ensino-aprendizagem de programação. A investigação contou com a participação de estudantes do gênero feminino ingressantes nos cursos de Licenciatura em Ciência da Computação e Bacharelado em Sistemas de Informação. Foram realizadas duas seções utilizando a metodologia Dojo propondo desafios para serem resolvidos pelas estudantes. Os resultados obtidos no estudo revelam que 50\% das participantes mostraram-se satisfeitas em participar das atividades. Em contrapartida, elas consideraram o grau de dificuldade regular $(33,3 \%)$ e ruim $(50 \%)$.

Os estudos descritos demonstram que ações como essas são importantes para a retenção de estudantes do gênero feminino em cursos de Computação. Dessarte, o presente artigo objetiva relatar uma investigação sobre ações de incentivo à permanência de estudantes ingressantes nos cursos de ES e CC na Universidade Federal do Ceará - Campus Russas realizando uma análise qualitativa sobre o impacto das ações.

\section{Apadrinhamento acadêmico}

O apadrinhamento acadêmico surgiu na Universidade Federal do Ceará - Campus de Russas no ano de 2019 como forma de acolher as alunas ingressantes dos cursos de ES e CC e apoiar a sua adaptação no ambiente acadêmico. A ideia principal do apadrinhamento consistia em definir para cada aluna ingressante interessada em participar da iniciativa, uma aluna veterana que seria sua madrinha, fornecendo orientações sobre o ambiente acadêmico quando necessário.

Para iniciar o apadrinhamento acadêmico, houve uma apresentação para as alunas ingressantes do semestre 2019/02 sobre o objetivo do apadrinhamento acadêmico. Em seguida, as alunas responderam a um questionário para caracterização do perfil e indicação de interesse (ou não) em participar da iniciativa. Nove alunas ingressantes aceitaram participar da iniciativa, de um total de 15 alunas. Então, foi 
realizado um sorteio para designar cada afilhada a uma madrinha. Com o intuito de facilitar a comunicação entre as alunas foi criado um grupo no WhatsApp.

As madrinhas forneceriam orientações e suporte para as alunas ingressantes sobre: o funcionamento do campus, dicas e experiências sobre disciplinas, oportunidades de bolsas, oportunidade de participação em eventos tecnológicos, projetos de pesquisa do campus, indicação de grupos de estudos e também na adaptação à cidade onde o campus está localizado. As alunas assumiram o papel de afilhadas, se comprometendo a interagir diretamente com as suas madrinhas.

Além do acompanhamento individual das madrinhas com suas respectivas afilhadas, foram definidas ações coletivas como encontros, palestras para que todas as alunas ingressantes participassem e interagissem, promovendo uma maior integração das alunas ingressantes com as demais alunas dos cursos de ES e CC. O projeto Meninas Digitais do Vale elaborou uma série de eventos semanais, como: rodas de conversa, exibição de filmes temáticos e dinâmicas para integração. Estes eventos eram abertos às alunas dos cursos de $\mathrm{ES}$ e $\mathrm{CC}$ e com foco nas alunas do apadrinhamento.

\section{Metodologia}

A metodologia adotada nesta pesquisa foi a pesquisa qualitativa com a adoção de entrevistas com alunas ingressantes participantes do apadrinhamento acadêmico e a metodologia Teoria Fundamentada nos Dadospara análise e interpretação dos dados obtidos. Esse estudo foi conduzido por alunas integrantes do projeto Meninas Digitais do Vale e consistiu nas etapas ilustradas na Figura 1.
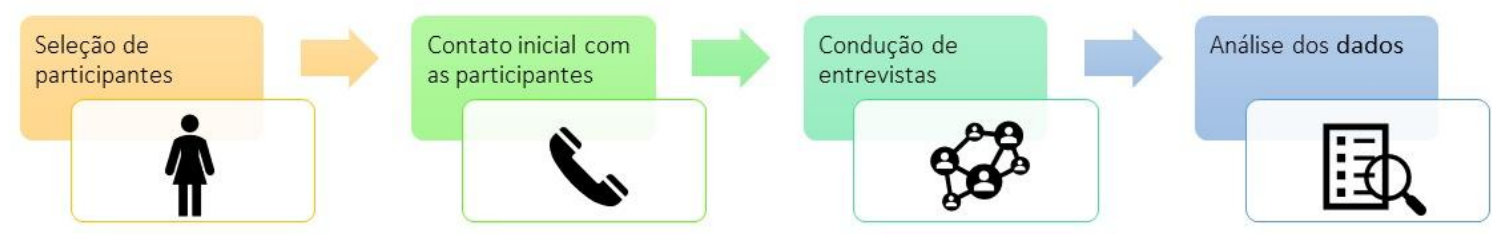

Figura 1. Processo metodológico

Seleção de participantes: as participantes da pesquisa foram alunas que ingressaram no semestre 2019.2 nos cursos de CC e ES da universidade UFC-Campus de Russas, semestre no qual o projeto iniciou as ações de apadrinhamento acadêmico. Com base em relatórios gerados pelo sistema acadêmico e fornecidos pela coordenação dos cursos, foi possível obter o contato (e-mail e telefone) atualizado das alunas.

Contato inicial com as participantes: realizou-se um contato inicial com as estudantes dos cursos mencionados, sendo seis ingressantes do curso de $\mathrm{CC}$ e nove ingressantes do curso de ES. Neste contato inicial, o objetivo da pesquisa foi explicado, assim como a importância da participação das estudantes na pesquisa.

Condução de entrevistas: para a condução das entrevistas, um roteiro foi elaborado contendo sete perguntas abertas (Figura 2). Devido à substituição das atividades acadêmicas presenciais pelas atividades remotas em decorrência da pandemia causada pelo COVID-19, publicado pelo Ministério da Educação (MEC) na portaria $\mathrm{n}^{\circ} 343$, de 17 de março de 2020, as entrevistas foram conduzidas por meio da rede social Whatsapp. As entrevistas foram realizadas ao longo de duas semanas. As pesquisadoras enviaram por meio de mensagens de texto o roteiro da entrevista e as alunas 
participantes enviaram suas respostas por meio de áudio. Inicialmente nove participantes aceitaram participar da pesquisa, porém uma participante desistiu no decorrer do período das entrevistas.

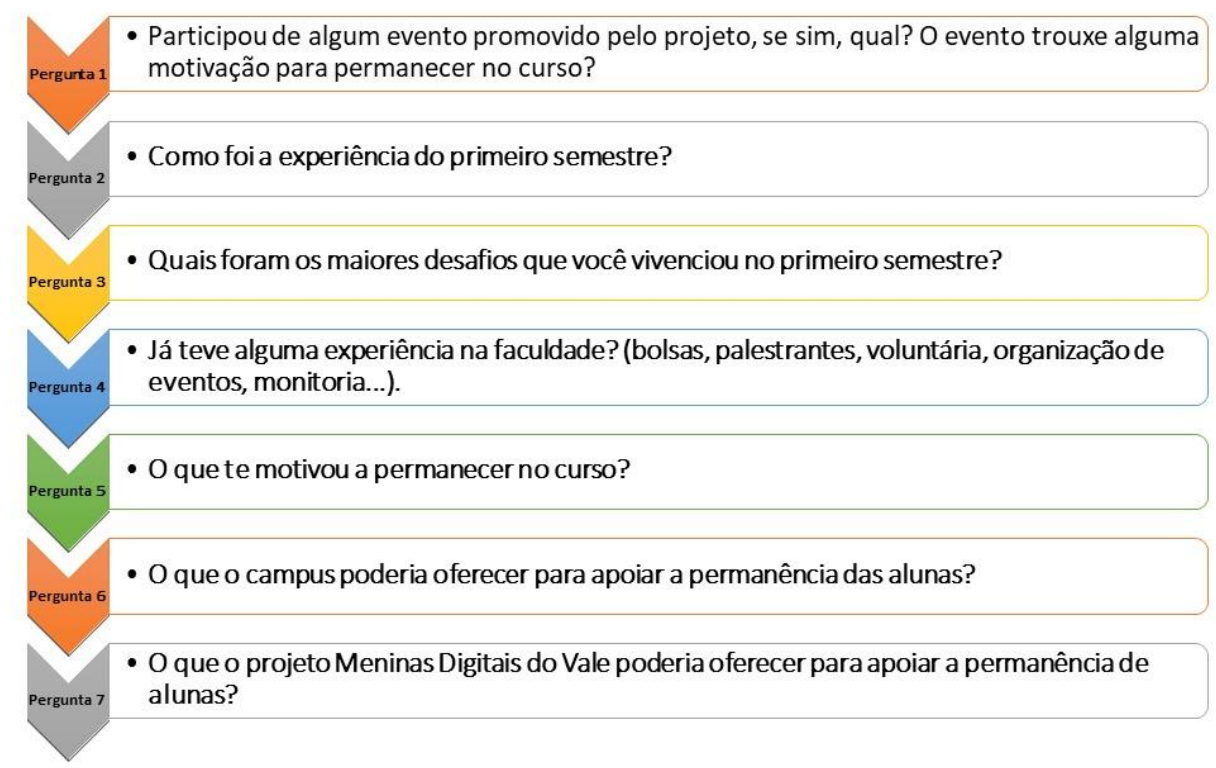

Figura 2. Perguntas utilizadas na entrevista.

Análise dos dados: De acordo com Barbosa (2017), a pesquisa qualitativa visa coletar e analisar dados não numéricos, a fim de atingir a profundidade da informação coletada ao invés da amplitude. Nesta pesquisa, a análise qualitativa serviu para analisar as respostas das alunas mediante questões sobre experiências e desafios no primeiro semestre, participação em eventos do projeto e da faculdade, motivos para a permanência no curso e influência do projeto para esse fator.

A metodologia utilizada para a análise dos dados foi o Teoria Fundamentada nos Dados, que consiste em uma abordagem para analisar dados a partir da codificação (Corbin e Strauss, 2014). No decurso do processo de codificação, fragmentos dos dados são utilizados como códigos e categorias. $\mathrm{O}$ código nomeia o fenômeno no qual o pesquisador está interessado. O processo de codificação pode ser dividido em três fases: codificação aberta, axial e seletiva. Para essa pesquisa utilizou-se somente a codificação aberta e axial. A codificação aberta envolve a quebra, a análise, a comparação, a conceituação e a categorização dos dados, enquanto a codificação axial consiste na identificação de categorias que reúnem diversos códigos.

A análise dos dados foi feita de forma qualitativa sobre os áudios enviados pelas alunas. Primeiramente, as pesquisadoras utilizaram a plataforma Google Voice para transcrever os áudios em um documento de texto. Em seguida, as respostas foram organizadas de acordo com cada pergunta e realizou-se os procedimentos de codificação dos dados com o auxílio da ferramenta ATLAS.ti. Moreira (2007) destaca o Atlas.ti como um software para a análise de dados qualitativos que oferece aprimorados recursos para a manipulação dos dados e representação da relação entre seus segmentos partindo de uma rede de linhas que ligam os códigos aos documentos que contém os dados. Duas pesquisadoras conduziram a codificação e posteriormente, outras duas pesquisadoras especialistas em análise qualitativa com GT validaram a codificação. 


\section{Resultados da Análise Qualitativa dos Resultados}

$\mathrm{O}$ uso de procedimentos de codificação possibilitou identificar as principais categorias de resultados, como: (i) sugestões de ações para o projeto, (ii) fatores motivacionais e (iii) desafios do primeiro semestre. Foram criadas redes a partir da união dos códigos relacionados por categoria. Os números abaixo de cada código representam o Grau de fundamentação teórica (indica quantas vezes este código foi identificado nos dados analisados) e Grau de densidade teórica (indica a quantidade de relacionamentos deste código com outros códigos ou categorias). As alunas participantes foram nomeadas de P1 a P8 como melhor forma de identificação e confidencialidade. Os resultados serão apresentados nas subseções seguintes para cada categoria identificada com o uso de redes e apresentação de citações para os códigos identificados, quando possível.

\subsection{Sugestões de ações para o projeto}

A rede criada teve como objetivo selecionar os códigos que representassem sugestões de melhoria para a realização das ações do projeto Meninas Digitais do Vale. Na rede destacam-se três códigos principais: promover mais encontros entre as alunas, conhecer o perfil das alunas e palestras para compartilhamento de experiência de mulheres na área (Figura 3).

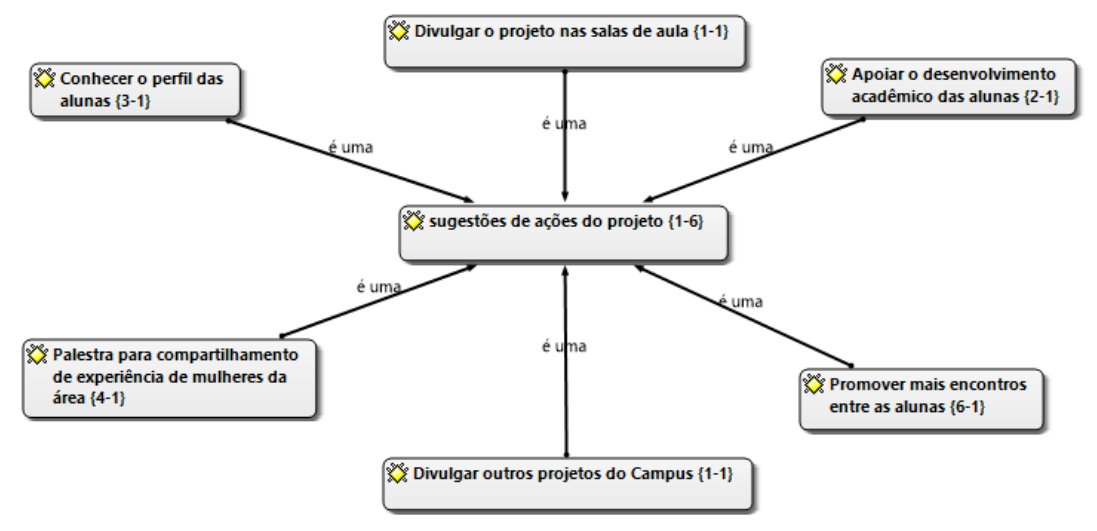

Figura 3. Rede de sugestões de ações para o projeto.

Promover mais encontros entre as alunas: apresentam os relatos das alunas que sugerem a realização de mais encontros entre meninas como nos relatos de P3 e P5:

P3 - "Ter mais momentos das meninas, porque no começo do meu primeiro semestre teve bastante, só que quando foi bem no finalzinho não tava tendo mais e eu senti bastante falta".

P5 - "Deveria continuar tendo esses encontros mensais para a gente conversar, bater um papo e apoiar umas às outras, eu acho bem importante e bem legal".

Conhecer o perfil das alunas: apresentam os relatos das alunas que sugerem que seja traçado o perfil das ingressantes para posteriormente desenvolver ações específicas para essas alunas como nos relatos de P1 e P6:

P1 - "Poderia tentar conhecer mais os interesses das alunas. Procurar também entender as dificuldades de cada uma e trabalhar nessa questão". 
P6 - "Precisa saber o que está fazendo elas saírem, como a faculdade, às vezes, os interesses que não batem."

Palestras para compartilhamento de experiências de mulheres na área: apresentam os relatos das alunas que sugerem ações por meio de palestras que compartilhem as experiências das mulheres na área de TI:

P1 - "Poderia de certa forma fazer mais palestras com as próprias professoras, dizendo para elas falarem um pouco de como foi o decorrer da carreira delas, as experiências e como ou o que as motivaram a permanecer no curso".

P5 - "A existência do projeto me ajudou muito na semana das mulheres, eu lembro que teve uma palestra e em uma parte as mulheres falaram das dificuldades que elas passaram, foi algo bem importante que eu aprendi muito".

P7 - "Ter palestras de mulheres que terminaram o curso e estão no mercado de trabalho, coisas assim que fazem com que a gente se inspire mais”.

\subsection{Fatores motivacionais}

A Figura 4 representa a rede criada a partir dos códigos que apresentam os motivos que levam as alunas ingressantes a continuarem na graduação. Nessa rede destacam-se os códigos de identificação com o curso e acolhimento do projeto.

Identificação com o curso: apresentam os relatos das alunas sobre o que as motivou a não desistir do curso de graduação, como nos relatos de P7 e P8.

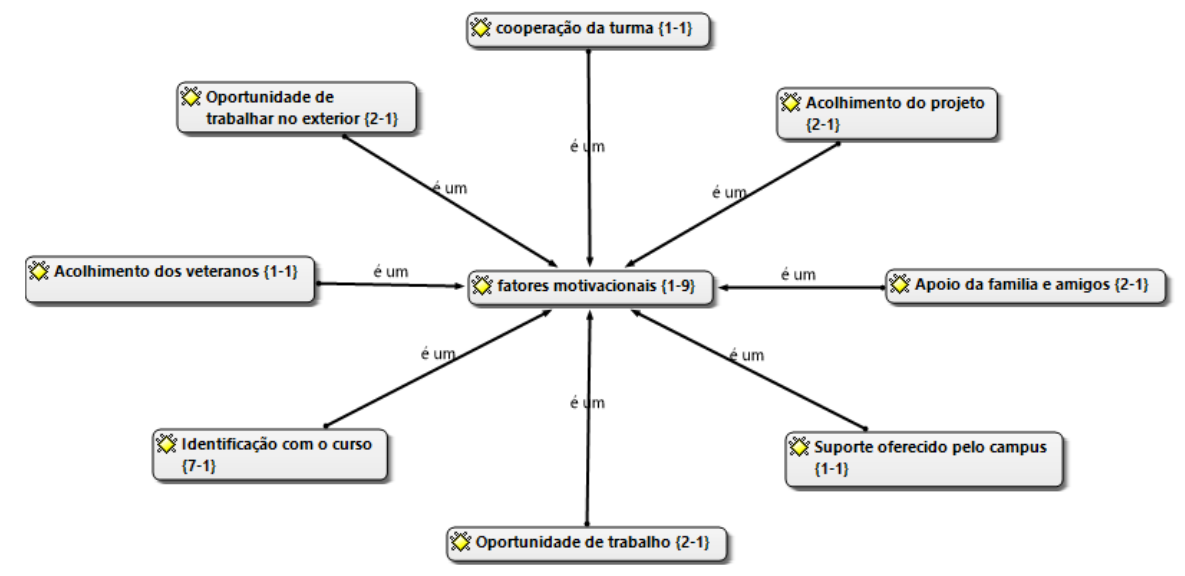

Figura 4. Rede de fatores motivacionais

P7 - "Eu não penso de maneira nenhuma em desistir do curso porque criei uma paixão gigantesca pelo curso de Ciência da Computação, antes não era minha primeira opção eu sempre quis fazer Física só que eu acabei indo para ciência da computação, me encaixei e vi que era algo que eu curtia e que seria legal para mim e hoje realmente vejo que me identifico muito com o curso".

P8 - "O que me fez continuar foi mais a questão de me identificar com o curso mesmo, eu gostei muito de fazer parte do curso e de ver outras mulheres que influenciam também no curso e que estão já concluindo a graduação. Ver também o quanto nós temos grande capacidade de estar em qualquer área que a gente quiser, então isso me motiva mais ainda”. 
Acolhimento do projeto: apresentam os relatos das ingressantes sobre o acolhimento que o projeto Meninas Digitais do Vale ofertou como nos relatos de P2 e P4.

P2 - "Me senti muito acolhida com o projeto Meninas Digitais do Vale e eu pude ver que sempre estão buscando formas de acolher as novatas, não são as novatas, mas todas as meninas do campus da área da TI".

P4 - "Me senti motivada porque eu vi um projeto de mulheres que me acolheu e mostrou a experiência das alunas que já concluíram o curso. Mostrou também a experiência das professoras e isso foi inspirador porque me fez pensar que eu posso sim me encaixar nessa área".

\subsection{Desafios do primeiro semestre}

A Figura 5 representa a rede criada a partir dos relatos das alunas ingressantes que apontaram os principais desafios enfrentados no primeiro semestre. Nessa rede destacam-se três códigos principais: Dificuldades nas disciplinas, adaptação no ambiente acadêmico e identificação com o curso.

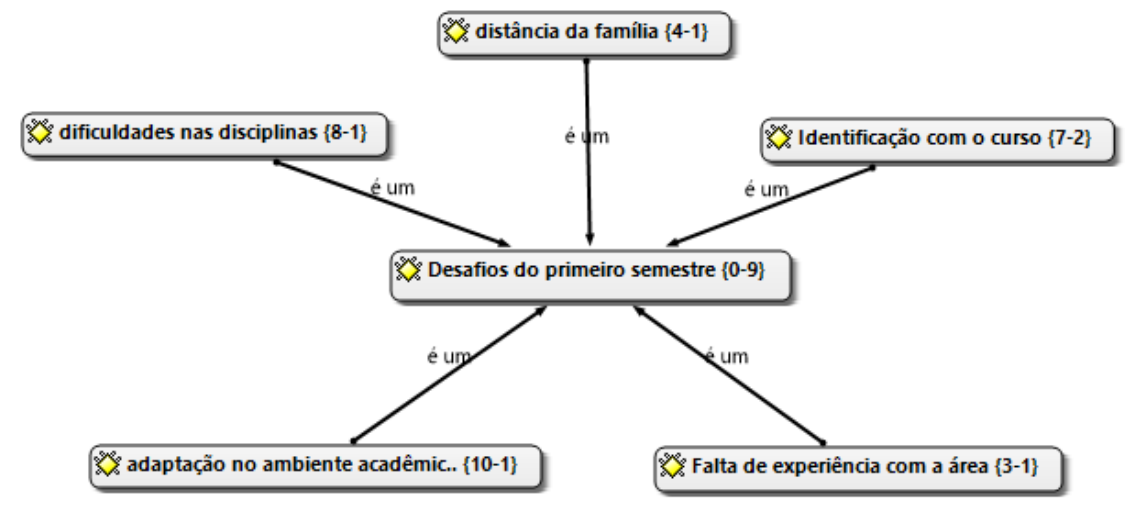

Figura 5. Rede dos desafios do primeiro semestre

Dificuldade nas disciplinas: apresentam os relatos das alunas ingressantes sobre o nível de dificuldade e entendimento das disciplinas do semestre inicial como nos relatos de P1, P2 e P7:

P1 - "Meu maior desafio no primeiro semestre sem dúvida foi com uma disciplina de programação por eu nunca ter tido contato [...] me desmotivou muito e eu não tava conseguindo absorver o conteúdo, foi um dos motivos de ter reprovado essa disciplina".

P7 - "Os desafios que eu encontrei no primeiro semestre foram mais em questões das cadeiras, eu não tinha uma base sobre os conteúdos e complicou muito”.

Adaptação no ambiente acadêmico: apresentam os relatos das alunas com as principais dificuldades de adaptação com o ambiente acadêmico:

P3 - "Eu vivenciei muitos momentos dificeis, tudo foi em questão de adaptação na faculdade, ao ambiente, questão de horário e essas coisas”.

P8 - "Eu não tinha uma rotina de estudar, por isso eu demorei um pouco a me adaptar ao ambiente acadêmico, o que acabou me forçando a sair da minha zona de conforto, reformular meus horários e a me planejar mais". 
Identificação com o curso: apresentam os relatos das alunas que têm como principal dificuldade a identificação com o curso, como nos relatos de P4 e P8:

P4 - "No primeiro semestre meu maior desafio foi me identificar com o curso, pois no decorrer das aulas eu não me identificava".

P8 - "Eu acho que os maiores desafios mesmo foi me encontrar e identificar com o curso e acompanhar as matérias que eu não entendia nada sobre o assunto".

\section{Discussão}

Por meio das respostas obtidas foi possível identificar o engajamento dessas estudantes nas ações realizadas. As participantes sugeriram propostas de novas ações citando também o sentimento de falta quando não são realizados encontros com frequência. Por meio desses encontros é possível fornecer apoio ao compartilhar experiências e desafios enfrentados por mulheres no decorrer da sua vida acadêmica e profissional, assim encorajando-as a seguir na área apesar das dificuldades. Assim, foi possível observar o impacto positivo que o projeto ocasionou por meio do apadrinhamento acadêmico. Notou-se que as ações mais focadas nas ingressantes trouxeram como diferencial uma maior aproximação entre as integrantes do projeto e as alunas ingressantes.

Outrossim, as respostas sugerem ações para conhecer o perfil das alunas, interesses, necessidades e os fatores que promovem a evasão. Entender o perfil do público alvo é importante para que o projeto consiga promover ações assertivas que se conectem com os gostos e preferências gerando engajamento. Por meio dos relatos também foram sugeridas palestras que compartilhem as experiências de mulheres na área de TI, como palestras com ex-alunas, professoras e profissionais da área sobre conteúdos técnicos e suas vivências. Tais ações podem promover a identificação e motivar a permanência nos cursos de ES e CC através da representatividade feminina. Em relação à evasão percebeu-se que tanto as alunas que participaram da iniciativa do apadrinhamento acadêmico como as que não participaram, continuam ativas nos cursos.

\section{Considerações Finais e Trabalhos Futuros}

Este trabalho objetivou investigar a experiência dos alunas ingressantes por meio da coleta de relatos a respeito das ações de apadrinhamento acadêmico desenvolvidas pelo projeto Meninas Digitais do vale e os principais desafios enfrentados pelas alunas, assim sendo possível traçar estratégias e ações que possam contornar e/ou amenizar esta situação. Devido ao distanciamento social, a coleta de dados foi realizada de forma remota com a condução de entrevistas. Com a realização da análise qualitativa foi possível verificar de maneira aprofundada como intervenções através de atividades simples como rodas de conversa, têm um impacto relevante na vida das envolvidas, dessa maneira incentivando a continuação e propagação dessas atividades. Ademais, a análise também permitiu coletar sugestões de melhorias e novas ações.

Com os resultados alcançados planeja-se tornar mais presentes ações do apadrinhamento acadêmico que visam facilitar a adaptação das estudantes ingressantes, a integração social e acadêmica, trabalhando assim para buscar a promoção de atividades voltadas para essas alunas, como: rodas de conversas, palestras e treinamentos. Pretende-se também, explorar mais a relação entre as madrinhas e as alunas ingressantes e realizar um mapeamento das sugestões de ações com intuito de verificar a viabilidade e implementá-las. 


\section{Referências}

Alves, G. M. D. S., da Silva, J. J., Dantas, R. D. Q., Dantas, V. F., de Figueiredo, R. V., and de Souza, G. C. (2017). Usando técnicas de aprendizagem colaborativa para incentivar o ensino-aprendizagem de programação entre as alunas de cursos de Computação. In Anais do XI Women in Information Technology. SBC.

Barbosa, M. W. (2017). Uma análise do uso de grounded theory em engenharia de software. Revista Produção Online, 17(1), 26-48.

Bordin, A., Finger, A., Gindri, L., and de Mello, A. (2020). Tutoria das Gurias: Uma ação de acompanhamento de alunas ingressantes em cursos de Computação. In Anais do XIV Women in Information Technology, (pp. 129-138). Porto Alegre: SBC.

BRASIL (2020). Portaria No 343, de 17 de março de 2020. Dispõe sobre a substituição das aulas presenciais por aulas em meios digitais enquanto durar a situação de pandemia do Novo Coronavírus - COVID-19.

Brito, L. Projeto de extensão da UFPB incentiva alunas da área de Tecnologia da Informação. G1 PB, 03 de março de 2020. Disponível em $<$ https://g1.globo.com/pb/paraiba/noticia/2020/03/07/projeto-de-extensao-da-ufpb-in centiva-alunas-da-area-de-tecnologia-da-informacao.ghtml $>$. Acesso em : 04 de mar. de 2021.

Corbin, J., and Strauss, A. (2014). Basics of qualitative research: Techniques and procedures for developing grounded theory. Sage publications.

da Silva, J.B., Braga, R.B., and Oliveira, C. T. (2018). Estratégias para Permanência e Êxito de Estudantes Mulheres em Cursos Superiores de Tecnologia da Informação e Comunicação. In Anais do XII Women in Information Technology. SBC.

Franzoia, F., Pires, F., and Pessoa, M. (2019). Mentorando meninas iniciantes em programação: um estudo de caso. In Anais do XIII Women in Information Technology (pp. 199-203). SBC.

Louzada, N., Santana, T., Assis, I., Braga, R., and Braga, A. (2019). Agindo sobre a diferença: atividades de empoderamento feminino em prol da permanência de mulheres em cursos de Tecnologia da Informação. In Anais do XIII Women in Information Technology (pp. 69-78). SBC.

Moreira, D. A. (2007). O uso de programas de computador na análise qualitativa: oportunidades, vantagens e desvantagens. Revista de Negócios, 12(2), 56-58.

ONU Mulheres Brasil. "Pensemos em igualdade, construção das mudanças com inteligência e inovação". Disponível em: <http://www.onumulheres.org.br/>. Acesso em: 21 de fevereiro de 2021.

Programaria. Por que o machismo cria barreiras para mulheres na tecnologia. Disponível em: <https://www.programaria.org/especiais/mulheres-tecnologia/>. Acesso em: 21 de fevereiro de 2021.

SBC Educação Superior em Computação Estatísticas-2019. Disponível em: $<$ https://www.sbc.org.br/documentos-da-sbc/category/133-estatisticas $>$. Acesso em: 14 de março de 2021. 